\title{
Minimally invasive plate osteosynthesis in metaphyseal fractures of tibia
}

\section{Ramesh Krishna K., Mohammed Ibrahim, Koteshwara Surendra Shreekantha}

Department of Orthopaedics, $\mathrm{BMC}$ and $\mathrm{RI}$, Bengaluru, Karnataka, India

\section{Address for the Correspondence:}

Dr. Shreekantha K S, Department of Orthopaedics, $B M C$ and $\mathrm{RI}$, Bengaluru, Karnataka, India. E-mail: dr.shreekantha.ks@ gmail.com

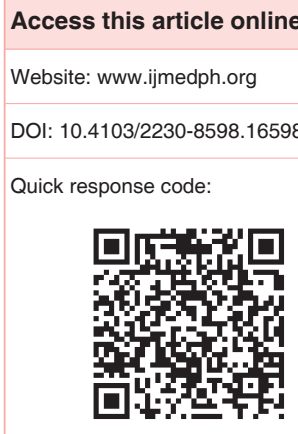

Introduction: Treating tibial metaphyseal fractures is still great challenge. However, two of most used techniques are locked intramedullary nail and minimally-invasive bridge plate. Minimally invasive plate osteosynthesis (MIPO) offers biological advantages. Reduced soft tissue dissection and exposition results in low surgical trauma and preservation of blood supply. Aim of study was to evaluate results of MIPO in treatment of metaphyseal fractures of tibia and to compare efficacy in treating metaphyseal fractures of tibia with other similar studies. Materials and Methods: This study was performed with 30 metaphyseal fractures of tibia with MIPO in hospitals attached to BMCRI. All cases were fresh fractures and traumatic. There were 12 proximal tibial and 18 distal tibial fractures. Temporary joint spanning external fixation was used for severe soft tissue injuries in 6 patients. All the fractures were stabilized by minimally invasive plating. Cases were followed up for an average of 14.1 months. Results: All fractures united. Proximal and disal tibia fractures united after an average of 6.3 and 6.6 months respectively. In proximal and distal tibia fractures, average range of motion achieved was $81.75^{\circ}$ and $48.8^{\circ}$ respectively. One patient with distal tibia fracture had a malunion with valgus alignment of more than $5^{\circ}$. Conclusion: Minimally invasive percutaneous plating facilitates in early mobilization of the patient which helps in healing of the fracture and prevents joint stiffness. It promotes early union as it does not disturb anatomy and physiology of vascularity at fracture site. There is minimal risk of infection and minimal blood loss.

Key words: Distal tibia, infection, locking plate, minimally invasive plate osteosynthesis, plateau fracture, soft tissue

\section{INTRODUCTION}

Fractures of tibia are one of the most common fractures encountered in orthopaedics. The subcutaneous location of the antero-medial surface of the tibia means that severe bone and soft tissue injury is not infrequent and there is a high incidence of open fractures compared to other long bones. Treating tibial metaphyseal fractures is still a great challenge.

Considering its anatomy, it is difficult to achieve reduction and maintain it in these fractures. Reduction is even more difficult when a fibular fracture is found at the same level as the tibia. This fracture pattern reflects a high-energy mechanism of trauma causing an increased angular and rotational instability, limb shortening and soft tissue injuries.

Conventional open reduction and internal fixation of such injuries results in extensive soft tissue dissection and periosteal injury, compromising the blood supply, and may be associated with high rates of infection, delayed union, and nonunion. Similarly, external fixation of metaphyseal tibial fractures may also be associated with a high incidence of pin site infection and loosening in up to $50 \%$ of cases and malunion rates of up to $45 \%$.

Minimally invasive plate osteosynthesis (MIPO) offers biological advantages. Reduced soft tissue dissection and exposition results in low surgical trauma and thus preservation of the blood supply is one of the main advantages of MIPO. Biological fixation is achieved with lesser evacuation of osteogenic fracture hematoma..$^{[1,3]}$

The aim of our study is to prospectively study the functional, clinical, radiological outcome of MIPO in tibial metaphyseal fractures and to understand the difficulties in procedure if any. 


\section{MATERIALS AND METHODS}

This study involved both male and female patients with metaphyseal fractures of tibia, who presented to Victoria hospital and Bowring and Lady Curzon hospitals, attached to Bangalore medical College and research institute, Bangalore. Thirty adult patients who had metaphyseal fractures of tibia including proximal and distal articular and periarticular fractures of tibia from October 2007 to September 2009. All the cases were fresh fractures and were traumatic in nature. Both closed and open fractures of type I and II according to Gustilo Anderson Classification were included. Paediatric fractures and pathological fractures were excluded.

Resuscitation was done in emergency room and temporarily stabilised with a splint in closed fractures. Open wounds were treated with wound irrigation and debridement and closure as needed and temporary joint spanning external fixation were applied until improvement of soft tissues.

Patients were operated with a small incision at one of the ends away from fracture site, and creating an epiperiosteal tunnel for suitable length passing the fracture site with a doubly angled periosteal elevator and tunnel opened on other side with an incision. Fracture reduced with traction and manipulation and suitable plate was slided and secured with at least six to eight cortices purchase. Entire procedure was performed under fluoroscopic imaging. A L or T buttress plate or a precontoured proximal tibia locking compression plate (LCP) is used for proximal metaphyseal fractures. A narrow tibia dynamic compression plate (DCP), low contact DCP or a pre contoured distal tibia LCP is used for fractures of the distal tibia. Careful soft tissue handling and preservation of periosteal tube and thereby fracture hematoma was a key in the surgery.

In case of articular extension of the fracture, the articular fragments were reduced anatomically and fixed with $\mathrm{K}$-wires. When a LCP is used for such fractures, the combination principle is applied where in lag screws and locking bolts are used.

In patients with severe soft tissue injuries, wherein the fracture is not suitable for immediate internal fixation, stage wise management is recommended. In the initial stage the intraarticular fracture fragments are reduced and fixed with K-wires, ORIF was done for fracture of fibula and a joint spanning external fixator until the soft tissues are suitable for internal fixation. This is determined when the oedema has sufficiently subsided and the soft tissues have healed which is indicated by the "wrinkle sign." In the second stage the external fixator is removed and the fracture of tibia fixed by minimally invasive plating.

Patient was allowed non weight bearing crutch walking on next postoperative day. Skin sutures were removed after adequate wound healing. Partial weight bearing crutch walking/walker commenced after 1 week, depending upon the type of fracture and rigidity of fixation. Further follow up is done at 6 weekly intervals and each patient was individually assessed clinically and radiographically according to the proforma. Detailed analysis of function of the patients with distal tibia fractures was done on the basis of following Ankle evaluation scoring system (Merchant and Dietz). Patients with proximal tibia fractures were evaluated by The American Knee Society Score (Insall Modification).

\section{RESULTS}

Thirty patients who had 30 fractures were available for evaluation. The duration of follow-up ranged from 9 to 22 months (average 14.1 months). There were 20 men (66.67\%) and 10 women $(33.34 \%)$ ranging in age from 21 to 70 years old, with an average age of 40.9 years.

Right side was involved in 14 (46.67\%) and left in 16 (53.33\%). Most of the fractures were caused by high energy trauma. Nine of the fractures were caused by pedestrian-automobile accidents $(30 \%)$, 14 by motor cycle accidents $(46.67 \%), 5$ by motor vehicle accidents $(16.67 \%), 2$ by falls $(6.67 \%)$.

None of the patients had associated fractures and injuries. 18 patients had distal tibia fractures $(60 \%)$ and 12 had proximal fractures $(40 \%)$. Of the distal tibia fractures, majority were of A2 type (22.2\%). Of the proximal tibia fractures, majority was also of A2 (25\%). And 26 of the fractures in our study were closed (86.67\%). Most of the patients in our study were operated 6-10 days after trauma (46.67\%). Of the proximal tibia fractures, $6(50 \%)$ were fixed with a LCP, $4(33.33 \%)$ were fixed with a DCP and $2(16.67 \%)$ were fixed with Butress plate. Of the distal tibia fractures, $7(38.89 \%)$ were fixed with DCP, 9 (50\%) were fixed with LCP and 2 (11.11\%) were fixed with LC DCP. Patient's satisfaction; 20 (66.67\%) patients were pleased, $9(30 \%)$ were satisfied and $1(3.33 \%)$ patient was unhappy.

In our study, among patients with fractures of distal tibia, 1 (5.55\%) patient had excellent result, $8(44.44 \%)$ patients had good results and $9(50 \%)$ had fair results. In our study, among patients with proximal tibia fractures, $2(16.67 \%)$ patients had excellent results, $4(33.33 \%)$ had good results and $6(50 \%)$ had fair results [Table 1].

\section{Statistics of surgery}

Preoperative soft tissue complications were present in $8(44.44 \%)$ patients with distal tibia fractures and in $2(16.67 \%)$ patients with proximal tibia fractures. Temporary external fixation was used for an average of 11 days in 6 patients. External fixation was used in $5(27.778 \%)$ patients with distal tibia fractures and $1(8.33 \%)$ patient with fracture of the proximal tibia. Fixation of the fibula fracture was done in $10(55.55 \%)$ of the 18 fractures of distal tibia and in none

\begin{tabular}{lcccc} 
Table 1: Functional outcome & \\
$\begin{array}{l}\text { Functional } \\
\text { results }\end{array}$ & $\begin{array}{c}\text { Distal tibia } \\
\text { number }\end{array}$ & Percentage & $\begin{array}{c}\text { Proximal } \\
\text { tibia number }\end{array}$ & Percentage \\
\hline Excellent & 1 & 5.55 & 2 & 16.67 \\
Good & 8 & 44.44 & 4 & 33.33 \\
Fair & 9 & 50 & 6 & 50 \\
Poor & 0 & & 0 & \\
\hline
\end{tabular}


of the patients with proximal tibia fracture. Our mean operation time was $90 \mathrm{~min}$ (range $60 \mathrm{~min}$. to $120 \mathrm{~min}$ ).

The end results of all 30 cases are summarized here. All the cases had a follow up between 9 and 22 months.

\section{Union}

Union was defined as the presence of bridging callus on two radiographic views and the ability of the patient to bear full weight on the injured extremity. All the fractures united. The proximal tibia fractures united after an average of 6.3 months. Fractures of the distal tibia united after an average of 6.6 months. The longest time to union was 32 weeks in 3 cases of distal tibia fracture and the delay in union was partly attributable to the initial soft tissue injury and patient compliance with treatment [Figures 1-3].

\section{Range of motion}

One of the essential aspects of treatment with MIPO is the ability to mobilise the patient early.

In distal tibia fractures, the average range of motion achieved was $48.8^{\circ}(69.7 \%)$. The range of motion was more than $80 \%$ in $11(61.11 \%)$ patients and was $<50 \%$ in one $(5.55 \%)$ patient. $2(11.11 \%)$ patients had $50 \%$ of range of motion.

In proximal tibia fractures, the average range of motion achieved was $81.75^{\circ}(60.55 \%)$. The range of motion was more than $70 \%$ in $4(33.33 \%)$ patients and was less than $50 \%$ in $4(33.33 \%)$ patients.

\section{Malunion}

A malunion was defined as angulation in coronal plane (varus-valgus) of more than $5^{\circ}$, in the saggital plane (anterior-posterior) angulation of $>10^{\circ}$, or more than $10 \mathrm{~mm}$ of shortening.

Malrotation was evaluated by comparing the amounts of internal and external rotation of the injured extremity with those of the uninjured extremity. Only one patient with distal tibia fracture had a valgus alignment of more than $5^{\circ}$. None of the patients had more than $10^{\circ}$ of angulation in saggital plane and none had a shortening of more than $10 \mathrm{~mm}$.

\section{Infection}

2 patients with proximal tibia fracture and 2 with distal tibia fracture developed superficial wound infection at plate insertion site which subsided within 1 week with intravenous antibiotics.

\section{Plate exposure}

2 patients with fracture of distal tibia had developed plate exposure within the $1^{\text {st }}$ week of surgery which was managed by wound dressing and secondary closure.

\section{DISCUSSION}

Metaphyseal fractures of the tibia are often associated with significant soft tissue injury. The key point in management of this injury is to recognize the importance of the soft tissue component. ${ }^{[4,5]}$

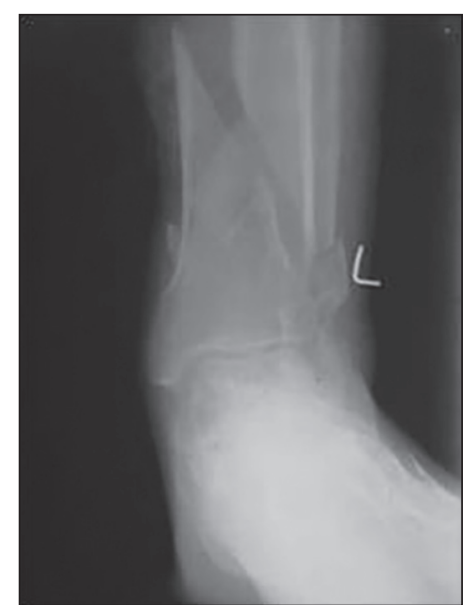

Figure 1: Preoperative X-ray

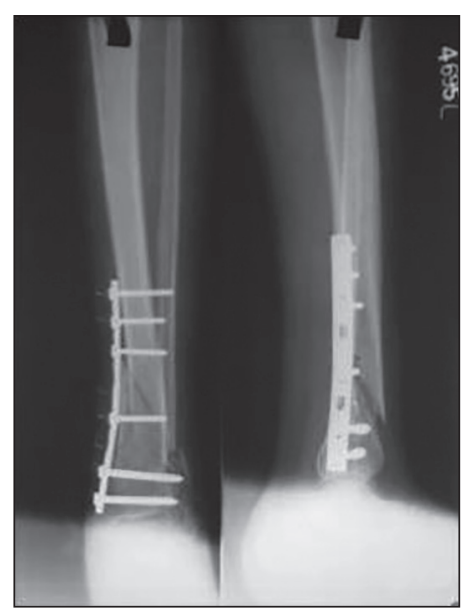

Figure 2: Immediate postoperative

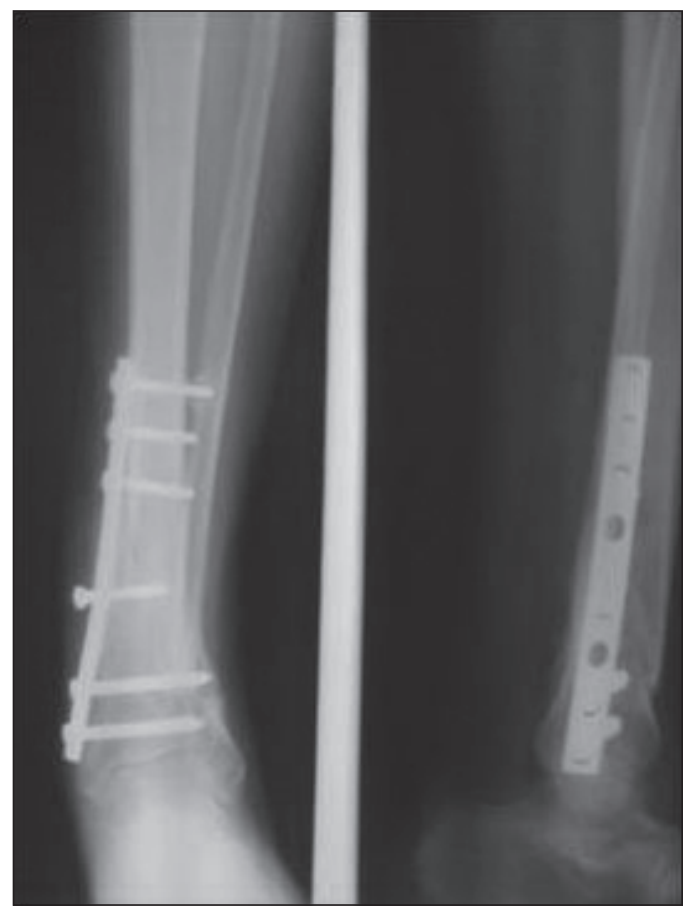

Figure 3: Follow-up after 5 months 
Failing to appreciate the soft tissue condition will invariably complicate the injury with infection, wound dehiscence or nonunion. Where the soft tissue injury is significant, bridging external fixation is advantageous for skeletal and soft tissue stabilisation. ${ }^{[6]}$

Definitive fixation is only advisable when the soft tissue allows it, when the 'wrinkle sign' is evident. Open fractures are treated with adequate debridement, washout, tetanus prophylaxis and broad spectrum antibiotics cover. ${ }^{[7]}$

The results of operative treatment are dependent on the severity of the initial injury and the quality and stability of the reduction. The mechanism of injury, the status of the soft tissues and the degree of comminution affect the long term clinical result. ${ }^{[8]}$

However, the most important factor is to achieve stable fixation and to allow early range of motion without unnecessary osseous and soft tissue devascularisation. ${ }^{[9]}$

Metaphyseal fractures of tibia pose a treatment dilemma to the orthopaedic surgeon, with little consensus on optimal management. ${ }^{[10,11]}$

Current treatment options include conservative management, percutaneous screw fixation, percutaneous periarticular plate fixation, external fixation and open reduction internal fixation with screws, K-wires and buttress plates. Problems associated with tibial plateau fractures include secondary loss of reduction leading to joint instability, poor alignment and posttraumatic arthritis. ${ }^{[12,13]}$

Biological fixation of tibial distal third fractures is beneficial and technically feasible. The advantages are: It reduces injuries on soft parts, it does not compromise bone vascularization and presents a low complication rate, especially when compared to open reduction and internal fixation. ${ }^{[14,15]}$

In current series 30 cases of metaphyseal fractures of the tibia, 18 with distal and 12 with proximal fractures, were treated by indirect reduction and minimally invasive percutaneous plating over a period of 2 years. They were followed up for an average of 14.1 months. The purpose of this study was to evaluate the end results of treatment in these patients.

\section{Age distribution}

The average age of all cases in this series was 40.9 years. The fracture is more common in the age group of $41-50$ years.

The average age in a study of 48 distal metaphyseal fractures of tibia conducted by the author showed that the average age was 35 years. ${ }^{[15]}$

In a study of 23 proximal tibia metaphyseal fractures of tibia conducted by the authors the average age was 53.5 years. ${ }^{[16]}$

\section{Sex distribution}

There were 20 male and 10 female patients showing male preponderance.
The sex distribution in a study by the author in the treatment of distal tibial metaphyseal fractures with MIPO showed that there were 15 men and 8 women. ${ }^{[2]}$

In a study by the authors in treatment of proximal tibia fractures, there were 18 males and 5 females. ${ }^{[17]}$

\section{Nature of violence}

Majority of the cases sustained fractures from road traffic accidents. Two patients had sustained fracture after a fall. Among R.T.A motor cycle accidents 14 cases (46.67\%) was most common mode of injury in present series.

A series reported by the author in treatment of distal tibial fractures, $44.7 \%$ fractures were due to road traffic accidents. ${ }^{[18]}$

\section{RESULTS}

In several reported series as well as in our series, the proximal and distal metaphyseal fractures of tibia have given excellent results. In our series $24(80 \%)$ fractures united within 7 months of injury, is comparable with the other series as well.

In the current series, there was no deep infection. There were 4 cases of superficial infection $(13.33 \%)$, compares favourably with other series reporting rate of $3.5-15.3 \%$.

The infection rate using MIPO is favourable compared with ORIF with plates (15-35\% deep infection rates) and also with external fixation (20-50\% pin track infection).

A malunion was defined as angulation in a coronal plane (varusvalgus) $>5^{\circ}$, saggital plane (anterior-posterior) angulation of $>10^{\circ}$ or $>10 \mathrm{~mm}$ of shortening.

In our series, only $1(3.33 \%)$ patient with distal tibia fracture had a valgus alignment of more than $5^{\circ}$. None of the patients had more than $10^{\circ}$ of angulation in saggital plane and none had a shortening of more than $10 \mathrm{~mm}$.

These results are comparable with the results of similar studies wherein the malunion rate is reported to be $2-5 \%$.

In our series no patient had implant failure. $2(6.66 \%)$ patients with distal tibia fracture developed plate exposure within the $1^{\text {st }}$ week of surgery which was effectively treated by regular wound dressing and secondary closure in 1 patient. This is also comparable to other similar studies which have reported a $0-10 \%$ incidence of plate exposure, most commonly at the distal insertion site.

In our series, in distal tibia fractures, the average range of motion achieved was $48.8^{\circ}(69.7 \%)$. The range of motion was more than $80 \%$ in $11(61.11 \%)$ patients.

In proximal tibia fractures, the average range of motion achieved was $81.75^{\circ}(60.55 \%)$. The range of motion was more than $70 \%$ in $4(33.33 \%)$ patients. 
At the end of the study each patient was individually asked regarding their opinion about the surgery and their return to premorbid status. $20(66.67 \%)$ patients were pleased, $9(30 \%)$ were satisfied and $1(3.33 \%)$ patient was unhappy.

\section{CONCLUSION}

Minimally invasive percutaneous plating seems feasible in metaphyseal fractures of the tibia. It facilitates in early mobilization of the patient which helps in healing of the fracture and prevents joint stiffness. It promotes early union as it does not disturb anatomy and physiology of vascularity at fracture site. There is minimal risk of infection and minimal blood loss.

\section{REFERENCES}

1. Farouk O, Krettek C, Miclau T, Schandelmaier P, Guy P, Tscherne H. Minimally invasive plate osteosynthesis and vascularity: Preliminary results of a cadaver injection study. Injury 1997;28:7-12.

2. Chandler RW. Principles of internal fixation. Rockwood and Greene's fractures in adults. $4^{\text {th }}$ ed., Vol. 1. Lippincott Williams \& Wilkins; 1996. p. 159-217.

3. Pai V, Coulter G, Pai V. Minimally invasive plate fixation of the tibia. Int Orthop 2007;31:491-6.

4. Weller S. Biological fracture fixation-What is this? Is it another traumatological fashion or an important aspect of operating technique? IGOF News 1997.

5. Mockford BJ, Ogonda L, Warnock D, Barr RJ, Andrews C. The early management of severe tibial pilon fractures using a temporary ring fixator. Surgeon 2003;1:104-7.

6. David JS, Donald RG. Fractures of the tibial plateaus. Clin Orthop 1975;109:166-77.

7. Rammelt S, Endres T, Grass R, Zwipp H. The role of external fixation in acute ankle trauma. Foot Ankle Clin 2004;9:455-74, vii.
8. Sands A, Grujic L, Byck DC, Agel J, Benirschke S, Swiontkowski MF Clinical and functional outcomes of internal fixation of displaced pilon fractures. Clin Orthop Relat Res 1998;347:131-7.

9. Crutchfield EH, Seligson D, Henry SL, Warnholtz A. Tibial pilon fractures: A comparative clinical study of management techniques and results. Orthopedics 1995;18:613-7.

10. Sands A, Gurjic L, Byck DC, Agel J, Benirschke S, Swiontkowski MF. Clinical and functional outcome of internal fixation of displaced pilon fracture. Clin Orthop 1998;347: 131-7.

11. Boldin C, Fankhauser F, Hofer HP, Szyszkowitz R. Three-year results of proximal tibia fractures treated with the LISS. Clin Orthop Relat Res 2006;445:222-9.

12. Konrath G, Moed BR, Watson JT, Kaneshiro S, Karges DE, Cramer KE. Intramedullary nailing of unstable diaphyseal fractures of the tibia with distal intraarticular involvement. J Orthop Trauma 1997;11:200-5.

13. Watson JT, Schatzker J. Tibial plateau fractures. In: Browner B, Jupiter J, Levine A, Trafton P, editors. Skeletal Trauma: Fractures, Dislocations, Ligamentous Injuries. $3^{\text {rd }}$ ed., Ch. 56. Philadelphia: Saunders; 2002.

14. Bonar SK, Marsh JL. Tibial Plafond Fractures: Changing Principles of Treatment. J Am Acad Orthop Surg 1994;2:297-305.

15. Krettek C. Concepts of minimally invasive plate osteosynthesis. Injury 1997;28 Suppl 1:S-A1-S-A2. DOI: http://dx.doi.org/10.1016/S00201383(98)95001-X

16. Bahari S, Lenehan B, Khan H, McElwain JP. Minimally invasive percutaneous plate fixation of distal tibia fractures. Acta Orthop Belg 2007;73:635-40.

17. Oh CW, Oh JK, Kyung HS, Jeon IH, Park BC, Min WK, et al. Double plating of proximal tibial fractures using minimally invasive percutaneous osteosynthesis technique. J Korean Fract Soc 2005;18:250-5.

18. Labronici PJ, Franco JS, da Silva AF, de Pina Cabral FM, da Silva Soares $\mathrm{M}$, de Toledo Lourenço PRB, et al. Treatment of distal fractures of the tibia. Acta Ortop Bras 2009;17:109-18.

How to cite this article: Krishna KR, Ibrahim M, Shreekantha KS. Minimally invasive plate osteosynthesis in metaphyseal fractures of tibia. Int J Med Public Health 2015;5:357-61.

Source of Support: Nil, Conflicts of Interest: None declared. 